\title{
A dimensão da pobreza, da fome e da desnutrição no Brasil
}

CARLOS AUGUSTO MONTEIRO

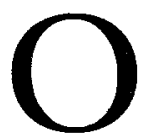

BJETIVA-SE, NESTE TEXTO, aferir e comparar a extensão e a distribuição no Brasil de três graves problemas: a pobreza, a fome e a desnutrição. Começaremos, em uma breve seção, por definir os problemas que iremos examinar. A seguir, explicitaremos os indicadores de que nos valemos, sua fundamentação lógica e as fontes de dados consultadas. Os resultados obtidos e as principais conclusões deste trabalho constituem seus tópicos finais.

\section{Definindo conceitos}

São pobres as pessoas que não suprem permanentemente necessidades humanas elementares como comida, abrigo, vestuário, educação, cuidados de saúde etc. Têm fome aqueles cuja alimentação diária não aporta a energia requerida para a manutenção do organismo e para o exercício das atividades ordinárias do ser humano. Sofrem de desnutrição os indivíduos cujos organismos manifestam sinais clínicos provenientes da inadequação quantitativa (energia) ou qualitativa (nutrientes) da dieta ou decorrentes de doenças que determinem o mau aproveitamento biológico dos alimentos ingeridos.

Ainda que compartindo terreno comum, os três conceitos descritos diferenciam-se. Esta diferenciação torna-se mais evidente através de exemplos. Um indivíduo, ou toda uma sociedade, poderá estar livre da fome e ainda assim ser pobre, bastando que sua pobreza se expresse através do não-acesso a educação e a cuidados de saúde, de condições insalubres de moradia ou através de outras carências materiais igualmente importantes. A situação inversa, ocorrência de fome na ausência de uma situação de pobreza, ocorre apenas excepcionalmente e sempre por tempo determinado, como por ocasião de guerras, cercos e cataclismas. Fome e desnutrição tampouco são conceitos equivalentes uma vez que, se toda fome leva obrigatoriamente à desnutrição, nem toda desnutrição se origina da deficiência energética das dietas, sobretudo na população infantil. A deficiência específica de macro e micronutrientes, o desmame precoce, a higiene alimentar 
precária e a ocorrência excessiva de infecções são causas bastante comuns da desnutrição infantil. Ainda que não equivalentes, os conceitos de pobreza e desnutrição são os que mais se aproximam, uma vez que o bom estado nutricional, sobretudo na criança, pressupóe o atendimento de um leque abrangente de necessidades humanas, que incluem não apenas a disponibilidade de alimentos, mas também a diversificação e a adequação nutricional da dieta, conhecimentos básicos de higiene, condições salubres de moradia, cuidados de saúde, entre outras.

\section{Medindo a extensão da pobreza, da fome e da desnutrição}

Alternativa interessante para se aferir a extensão da pobreza em uma dada sociedade consiste em se combinar indicadores da renda familiar a indicadores do acesso da população a bens e serviços essenciais, como moradia, saneamento, educação, serviços de saúde, entre outros (Seade, 1992). Os problemas metodológicos não são poucos, envolvendo desde a disponibilidade de informaçôes confiáveis para a construção dos diferentes indicadores até a dificuldade em estabelecer-se ponderaçóes adequadas para cada um deles.

Neste trabalho, utilizaremos as estimativas sobre a freqüência de pessoas pobres no país calculadas por Hoffmann (1994) e baseadas apenas na renda familiar per capita. O autor usa como fonte de dados a Pesquisa Nacional por Amostragem de Domićlio de 1990 e adota como linba de pobreza a renda familiar equivalente a $1 / 4$ de salário mínimo por pessoa.

A aferição da ocorrência da fome pode ser feita através da avaliação sistemática do consumo energético diário médio dos indivíduos, diante de suas necessidades diárias médias em energia. Entretanto, de modo mais prático, a aferição da ocorrência da fome em nível populacional pode ser feita a partir da avaliação das reservas energéticas dos indivíduos, representadas pelo seu tecido adiposo. $\mathrm{Na}$ população adulta esta avaliação permite a detecção da deficiência energética, sem maiores dificuldades e com razoável sensibilidade, por meio da análise da relação peso/altura dos indivíduos ou, mais especificamente, pelo cálculo do chamado Índice de Massa Corporal (peso expresso em $\mathrm{kg}$ dividido pelo quadrado da altura expressa em metros).

Na população infantil, o diagnóstico da deficiência energética através da avaliação da relação peso/altura é menos seńsível uma vez que, com freqüência, sobretudo nos casos leves e moderados, a deficiência energética em crianças se expressa unicamente pelo retardo global do crescimento. Tal retardo, por outro lado, não é específico da deficiência energética das dietas, mas sim manifestação 
comum de virtualmente todas as deficiências nutricionais na criança, sejam decorrentes de outras deficiências na dieta, como as de proteína, vitaminas ou minerais, sejam originárias de práticas alimentares inadequadas e mesmo de processos infecciosos freqüentes.

A aferição da ocorrência da desnutrição envolve procedimentos clínicos diversos que incluem anamnese, exame físico e provas laboratoriais. $\mathrm{Na}$ população infantil, a mais vulnerável à desnutrição, destaca-se, entre as provas diagnósticas, por sua elevada sensibilidade, a avaliação do crescimento físico. Esta avaliaçăo, como já se comentou, é capaz de indicar a ocorrência da desnutrição infantil independentemente dos fatores ambientais que a tenham originado.

Neste trabalho avaliaremos a prevalência da fome e da desnutrição a partir, respectivamente, do estudo da distribuiçāo do Índice de Massa Corporal da população adulta e do estudo da distribuição da relação altura/idade da população de crianças menores de cinco anos. Em ambos os casos, valer-nos-emos da Pesquisa Nacional sobre Saúde e Nutrição - Pnsn - realizada pelo Instituto Brasileiro de Geografia e Estatística - Ibge - em 1989, estudando uma amostra representativa de cerca de 14 mil famílias brasileiras, incluindo mais de sete mil crianças menores de cinco anos e mais de 25 mil adultos com idades a partir de 25 anos.

\section{A dimensão da pobreza, da fome e da desnutrição}

\section{$A$ dimensão da pobreza}

A tabela 1 resume as estimativas de Hoffmann quanto a situação da pobreza no Brasil no inicio da década de 90. Pessoas vivendo abaixo da linha de pobreza de 0,25 salário mínimo correspondiam, em 1990, a quase $1 / 4$ do total da população e integravam um contingente de 32,9 milhões de brasileiros. As prevalências regionais da pobreza mostram variaçóes importantes, destacando-se a desvantagem sistemática das populaçóes rurais diante das populações urbanas, e da região Nordeste frente às demais. A população com maior índice de pobreza, mais de $60 \%$ das pessoas com renda abaixo da linba de pobreza, vivia nas áreas rurais do Nordeste; a seguir vinha a população rural do Centro-Sul e a população urbana do Nordeste, ambas com pouco mais de $30 \%$ de pessoas pobres; em melhor situação, encontravam-se a população urbana da região Norte, $16 \%$ de pobres, $e$ a população urbana das regiōes do Centro-Sul do país, onde apenas 8 a $10 \%$ das pessoas estavam abaixo da linba de pobreza. Estimativas do mesmo autor dão conta que o quadro encontrado em 1990 persistiu, com pequenas variaçóes, ao longo de toda a década de $\mathbf{8 0}$. 
Tabela 1

Prevalência (\%) de indivíduos com renda familiar inferior a linha de pobreza de 0,25 salário mínimo per capita*. Brasil, 1990.

\begin{tabular}{lrrl}
\hline & \multicolumn{2}{c}{ Áreas } & \\
\cline { 2 - 3 } Região & Urbana & Rural & Total \\
\hline Norte & 16,2 & - & 16,2 \\
Nordeste & 31,8 & 62,1 & 44,9 \\
Sudeste & 8,6 & 32,3 & 12,0 \\
Sul & 8,4 & 32,4 & 16,2 \\
Centro-Oeste & 10,5 & 33,2 & 16,7 \\
\hline Brasil & $14,3^{\circ}$ & 46,8 & 22,8 \\
\hline
\end{tabular}

* Não inclui as famílias que não declaram rendimento. A unidade salário mínimo é o valor real do salário mínimo vigente em outubro de 1981 e o deflator usado é o Inpc restrito.

** Apenas as áreas urbanas foram estudadas.

Fonte: Adaptado de Hoffmann, 1994.

\section{$A$ dimensão da desnutrição}

Conforme antecipamos, a dimensão da desnutrição no país será buscada a partir da avaliação de crescimento infantil, mais especificamente, do computo das crianças menores de cinco anos com alturas aquém de dois desvios-padrão da altura média esperada para idade e sexo, de acordo com o padrão internacional de crescimento recomendado pela Organização Mundial de Saúde - OMS (WHO Working Group, 1986). Crianças com alturas tão baixas quanto as referidas são encontradas, em populações bem-nutridas, em proporção não-superior a 2-3\% e correspondem, neste caso, à fração normal de crianças geneticamente pequenas. Quando presentes em proporçóes superiores, crianças de baixa estatura passam a refletir a prevalência do retardo de crescimento e da desnutrição infantil na população.

A tabela 2 apresenta a freqüência de crianças de baixa estatura nas diferentes regiões do país, tal como estimada pela Pesquisa Nacional sobre Saúde e Nutrição de 1989. Inicialmente, observa-se que, em todas as regiōes, a frequiência de crianças de baixa estatura excede em muito a frequiência de $2-3 \%$, o que evidencia a natureza endêmica da desnutrição infantil e de sua disseminaçáo por todo o país. No Brasil como um todo, crianças de baixa estatura - ou crianças desnutridas - representavam $15,4 \%$ do total da populaçáo infantil, ou cerca de $2,5 \mathrm{mi}$ lhões de crianças. À semelhança da pobreza, o retardo do crescimento e a desnutrição infantil se distribuem de forma desigual no território brasileiro. Novamente, vemos as populações rurais em desvantagem, ainda que desta vez os contrastes com as populações urbanas sejam menos intensos. Os contrastes são mais intensivos, desta vez, entre as regióes Norte e Nordeste - 23 e $27,3 \%$ de crianças 
desnutridas - e as regióes do Centro-Sul $-8 \%$ a $9 \%$ de crianças desnutridas.

Tabela 2

Prevalência de crianças menores de cinco anos com retardo de crescimento*. Brasil, 1989.

\begin{tabular}{lccc}
\hline & \multicolumn{2}{c}{ Áreas } \\
\cline { 2 - 3 } Região & Urbana & Rural & Total \\
\hline Norte & 23,0 & - & 23,0 \\
Nordeste & 23,9 & 30,7 & 27,3 \\
Sudeste & 7,2 & 12,7 & 8,1 \\
Sul & 7,0 & 11,7 & 8,7 \\
Centro-Oeste & 7,4 & 10,2 & 8,2 \\
\hline Brasil & 12,3 & 22,4 & 15,4 \\
\hline
\end{tabular}

* Crianças com altura aquém de dois desvios-padrăo dos valores médios esperados para idade e sexo (padrão Nchs/OMS).

Fonte: Pnsn, 1989.

O uso sistemático do indicador altura/idade e do padrão internacional de crescimento da OMS em inquéritos nutricionais realizados a partir na década de 80 (De Onis et al., 1993) permite que a prevalência da desnutriçáo infantil no Brasil possa ser comparada à encontrada em outros países em desenvolvimento. Próximo ao Brasil encontra-se, por exemplo, o Paraguai $(16,6 \%$ de crianças desnutridas) país latino-americano cujo PIB per capita à época do inquérito (1990) representava pouco mais da metade do PIB per capita brasileiro em 1989 (US\$ 2.792 contra US\$ 4.951, valores já ajustados pela paridade do poder de compra conforme metodologia desenvolvida pelas Naçóes Unidas) (Undp, $1992 ; 1993)$.

Com relação às regióes brasileiras (figura 1 ), encontra-se equivalente para o Norte e o Nordeste em diversos países africanos de grande pobreza (PIB ajustado de menos de mil dólares per cápita) como, por exemplo, Mali em 1987 (25\% de crianças desnutridas) e Gana em 1988 (30,5\% de crianças desnutridas). O mesmo paralelo irá situar Sul, Sudeste e Centro-Oeste do país junto a um pequeno grupo privilegiado de países em desenvolvimento que apresentam menos de $10 \%$ de crianças desnutridas. Este grupo de países, todos de pequena população, inclui algumas ilhas do Garibe com níveis de renda excepcionalmente elevados para países em desenvolvimento (PIB ajustados entre 6 e 8 mil dólares per capita) e alguns países com níveis de renda modestos (PIB ajustados entre 2 e 4 mil dólares per capita), porém com sistemas de saúde e seguridade social reconhecidamente eficientes, como a Costa Rica, a Jamaica e o Chile. 


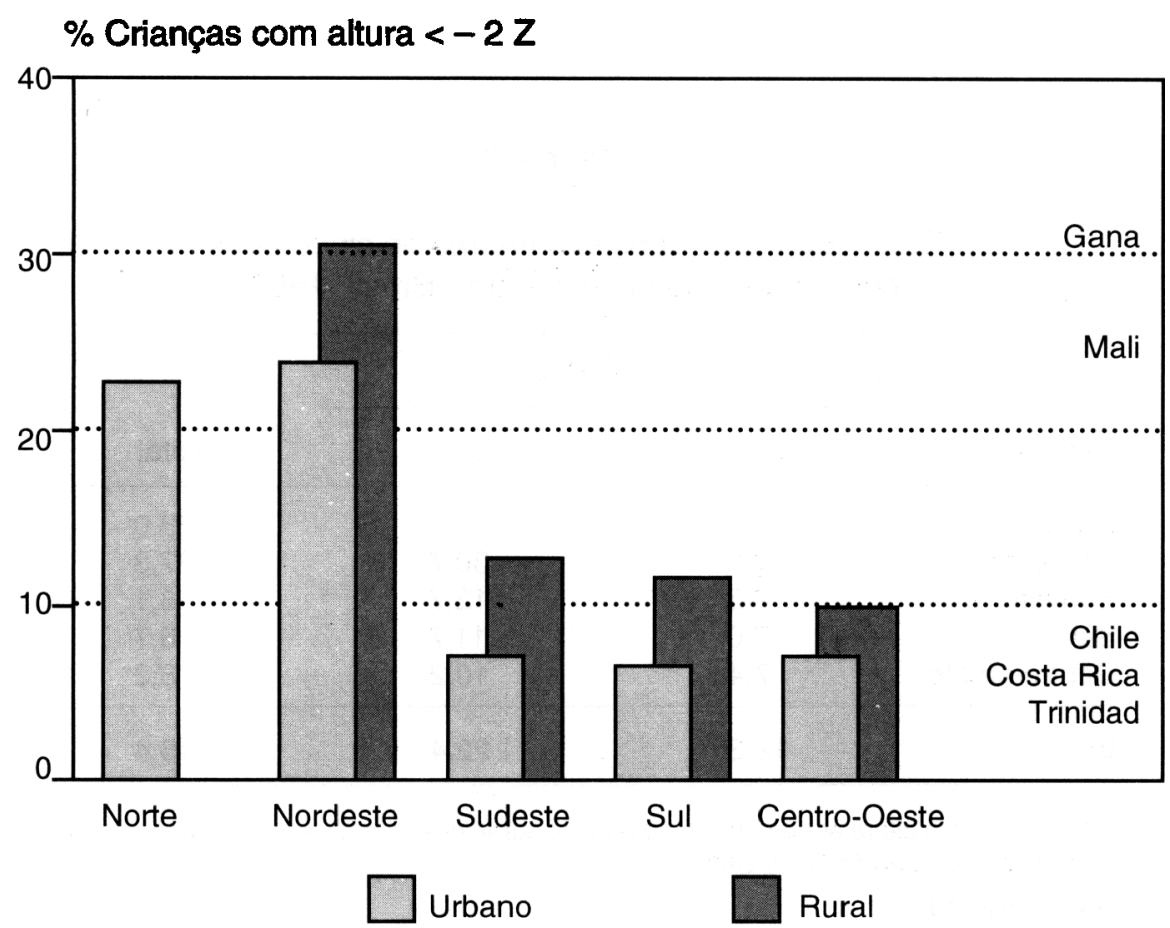

Fonte: Pnsn, 1989.

Figura 1: Prevalência da desnutrição infantil. Brasil, 1989.

No sentido de dar mais detalhes à distribuição espacial da desnutrição infantil no Brasil, procuramos verificar a prevalência de crianças de muito baixa estatura nos diferentes estados brasileiros. A amostra da Pnsn permite estimativas razoáveis para 16 estados (tabela 3 e figura 2 ).

Repetindo o visto para as regióes brasileiras, observam-se dois grupos distintos: o primeiro, constituído por estados do Sul, Sudeste e Centro-Oeste onde a freqüência de retardos severos de crescimento fica entre $4,9 \%$ e $11,6 \%$; o segundo grupo, constituído apenas por estados do Norte e do Nordeste, onde a mesma freqüência se situa entre $16,7 \%$ e $37,4 \%$.

Dentro do primeiro grupo de estados, que ocupa grosso modo a metade Sul do país, Santa Catarina e São Paulo comparam-se a Trinidad-Tobago; Mato Grosso do Sul e Rio Grande do Sul à Costa Rica; Goiás, Rio de Janeiro e Minas Gerais lembram Chile, Mato Grosso e Paraná assemelham-se ao Kuwait.

No segundo grupo de estados, que ocupa a metade Norte do país, algumas equivalências puderam ser encontradas com países latino-americanos muito pobres como a Nicarágua ou El Salvador (frequiência de crianças desnutridas de 
$21,8 \%$ e $29,9 \%$, respectivamente). É com os países pobres africanos, entretanto, que a comparação se mostrou exemplar, na qual o Amazonas é a Costa do Marfim, a Bahia é o Djibuti, o Ceará é o Congo, Pernambuco é Zimbábue e o Pará é o Togo; Alagoas e Maranhão, os dois estados brasileiros com maior prevalência de retardo do crescimento, estáo entre Serra Leoa e Zâmbia, pouco faltando para que pudessem ser o Haiti.

Tabela 3

Percentual de crianças com retardo severo de crescimento em diferentes estados brasileiros e em países selecionados (1980-1989).

\begin{tabular}{lrll}
\hline Estados do Brasil & $\%$ & Países & $\%$ \\
\hline Santa Catarina & 4,9 & Trinidad-Tobago & 5,0 \\
São Paulo & 5,6 & & \\
\hline Mato Grosso do Sul & 6,1 & Costa Rica & 7,8 \\
Rio Grande do Sul & 8,2 & & \\
\hline Goiás & 9,4 & Chile & 9,6 \\
Rio de Janeiro & 9,9 & & \\
\hline Minas Gerais & 10,6 & & 11,3 \\
\hline Mato Grosso & 11,1 & Kuwait & 17,2 \\
\hline Paraná & 11,6 & & 22,2 \\
\hline Amazonas & 16,7 & Costa do Marfim & 27,1 \\
\hline Bahia & 22,0 & Djibuti & 29,0 \\
\hline Ceará & 27,6 & Congo & 29,6 \\
\hline Pernambuco & 28,6 & Zimbábue & 34,7 \\
\hline Pará & 29,4 & Togo & 40,6 \\
\hline Alagoas & 36,8 & Serra Leoa & Zâmbia \\
\hline Maranhão & 37,4 & Haiti & \\
\hline
\end{tabular}

É importante destacar neste momento que o excesso de crianças desnutridas na regiāo Nordeste deve-se a dois fatores igualmente ponderáveis: o menor nível de renda das familias nordestinas diante das famílias do Centro-Sul do país e a maior prevalência de desnutrição no Nordeste, mesmo em idênticos estratos de renda. Para exemplificar, nas regióes do Centro-Sul $24 \%$ das crian- 
ças examinadas pela Pnsn pertenciam a famílias pobres (linha de pobreza equivalente à utilizada por Hoffmann) e $18 \%$ delas eram desnutridas. Já na região Nordeste, $67 \%$ das crianças eram pobres e $35 \%$ delas desnutridas. Fatores independentes da renda familiar parecem ser ainda mais importantes na região Norte; nesta, a frequiência de crianças pobres não foi muito superior à encontrada no Centro-Sul do país - $\mathbf{2 8 \%}$ - sendo estas crianças, entretanto, afetadas por prevalência de desnutrição de $40 \%$, superior à encontrada na região Nordeste para o mesmo estrato de renda.

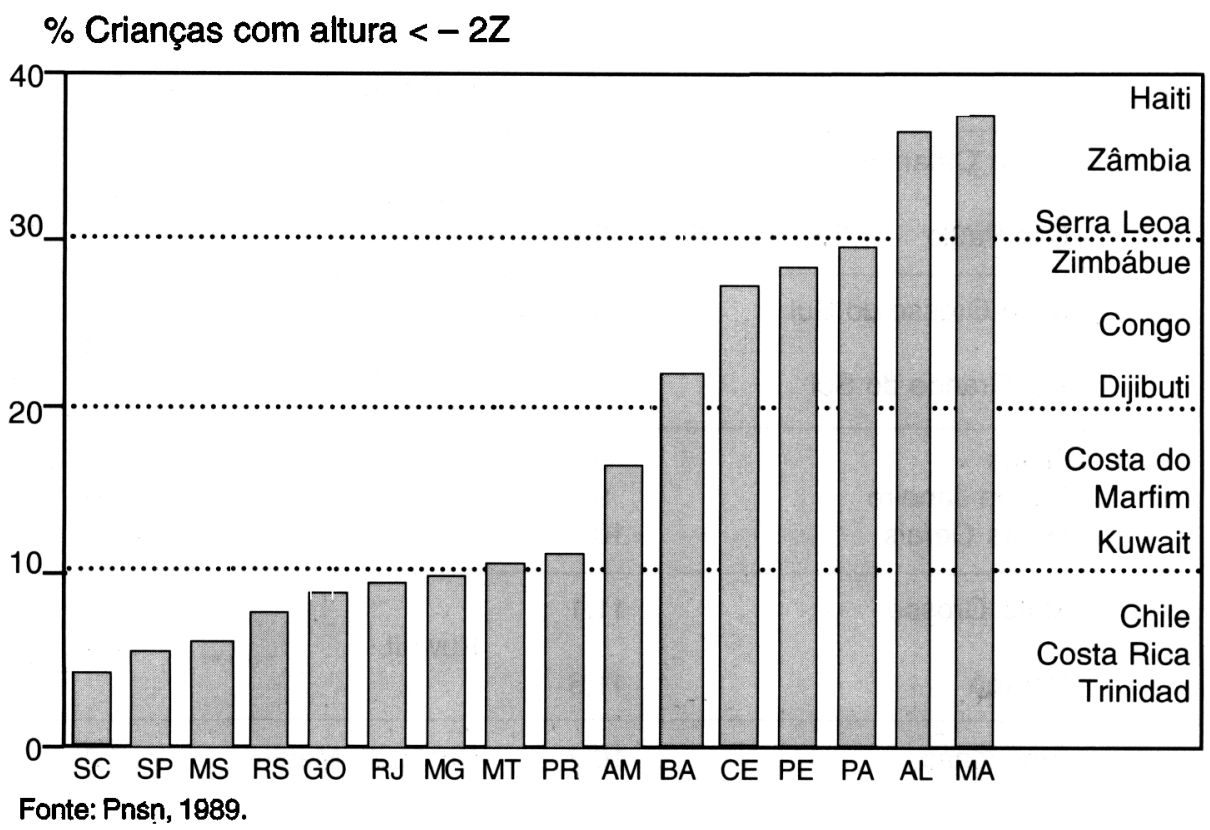

Figura 2: Prevalência da desnutrição infantil em estados selecionados. Brasil, 1989.

\section{$A$ dimensão da fome}

Conforme referido anteriormente, buscaremos a dimensão da fome no Brasil a partir do estudo da distribuição das reservas energéticas da população brasileira de adultos, tal como estudada pela Pnsn, mais particularmente a partir do cálculo da prevalência de indivíduos de mais de 24 anos de idade, com Indice de Massa Corporal - IMC inferior a $18,5 \mathrm{~kg} / \mathrm{m}^{2}$.

Segundo Comitê de Especialistas da Organização Mundial de Saúde -OMS, reunido em Genebra em 1993, valores de IMC inferiores a $18,5 \mathrm{~kg} / \mathrm{m}^{2}$ indicam nível mínimo de reservas energéticas no adulto e são encontrados em populaçóes que não apresentam restrição alimentar em apenas 3\% a $5 \%$ das pessoas. Esta fração representaria o contingente de indivíduos constitucionalmente magros em 
uma população. Para o mesmo Comitê, valores baixos de IMC (inferiores a 18,5 $\mathrm{kg} / \mathrm{m}^{2}$ ), presentes entre $5 \%$ e $9 \%$ das pessoas, caracterizariam populaçóes expostas à baixa prevalência de déficits energéticos, o que justificaria a necessidade de monitorizar o problema e estar alerta para sua eventual deterioração (nesta situação, estariam Cuba e México, por exemplo). Freqüências entre 10\% e 19\% já caracterizariam populaçóes expostas a prevalência moderada de déficits energéticos (nesta situação, cita-se o exemplo da China). Frequiências entre $20 \%$ e $39 \%$ caracterizariam prevalências altas de déficits energéticos (nesta situação há o exemplo da Etiópia). Finalmente, valores baixos de IMC em mais de $\mathbf{4 0 \%}$ da população caracterizariam prevalências muito altas de déficits energéticos (como, por exemplo, as encontradas na Índia) (OMS, 1994 - comunicação pessoal).

A tabela 4 apresenta a prevalência de indivíduos com baixo Índice de Massa Corporal, ou, mais simplesmente, individuos magros, nas diferentes regióes brasileiras. Observa-se que nas áreas urbanas a frequiência de indivíduos magros tende a ficar abaixo ou muito próxima de $\mathbf{5 \%}$, o que indicaria que as áreas urbanas do país estariam relativamente protegidas de déficits energéticos. Nas áreas rurais o quadro é diverso. Apenas nas áreas rurais do Sul do país a proporção de pessoas magras não ultrapassa o limiar de 5\%. No Centro-Oeste e Sudeste rurais, a proporção de individuos magros fica entre $6 \%$ e $7 \%$ e no Nordeste rural chega a 9,4\%. Tal situação parece indicar a exposiçáo, ainda que em grau leve, da maioria da população rural brasileira a déficits energéticos, sugerindo que o problema carece de monitorização. O quadro é ainda mais crítico na região Nordeste, onde a prevalência de valores baixos de IMC se aproxima do limiar que já caracterizaria a prevalência moderada de déficits energéticos (10\%) (figura 3).

Tabela 4

Prevalência (\%) de adultos (25 anos e mais) com baixo Índice de Massa Corporal (IMC)*.

Brasil, 1989.

\begin{tabular}{lccc}
\hline & \multicolumn{3}{c}{ Áreas } \\
\hline Região & Urbana & Rural & Total \\
\hline Norte & 4,4 & - & 4,4 \\
Nordeste & 5,2 & 9,4 & 6,8 \\
Sudeste & 3,9 & 7,2 & 4,4 \\
Sul & 2,6 & 4,1 & 3,0 \\
Centro-Oeste & 4,2 & 6,3 & 4,7 \\
\hline Brasil & 4,0 & 7,5 & 4,9 \\
\hline
\end{tabular}

* Adultos com IMC inferior a $18,5 \mathrm{~kg} / \mathrm{m}^{2}$.

Fonte: Pnsn, 1989. 


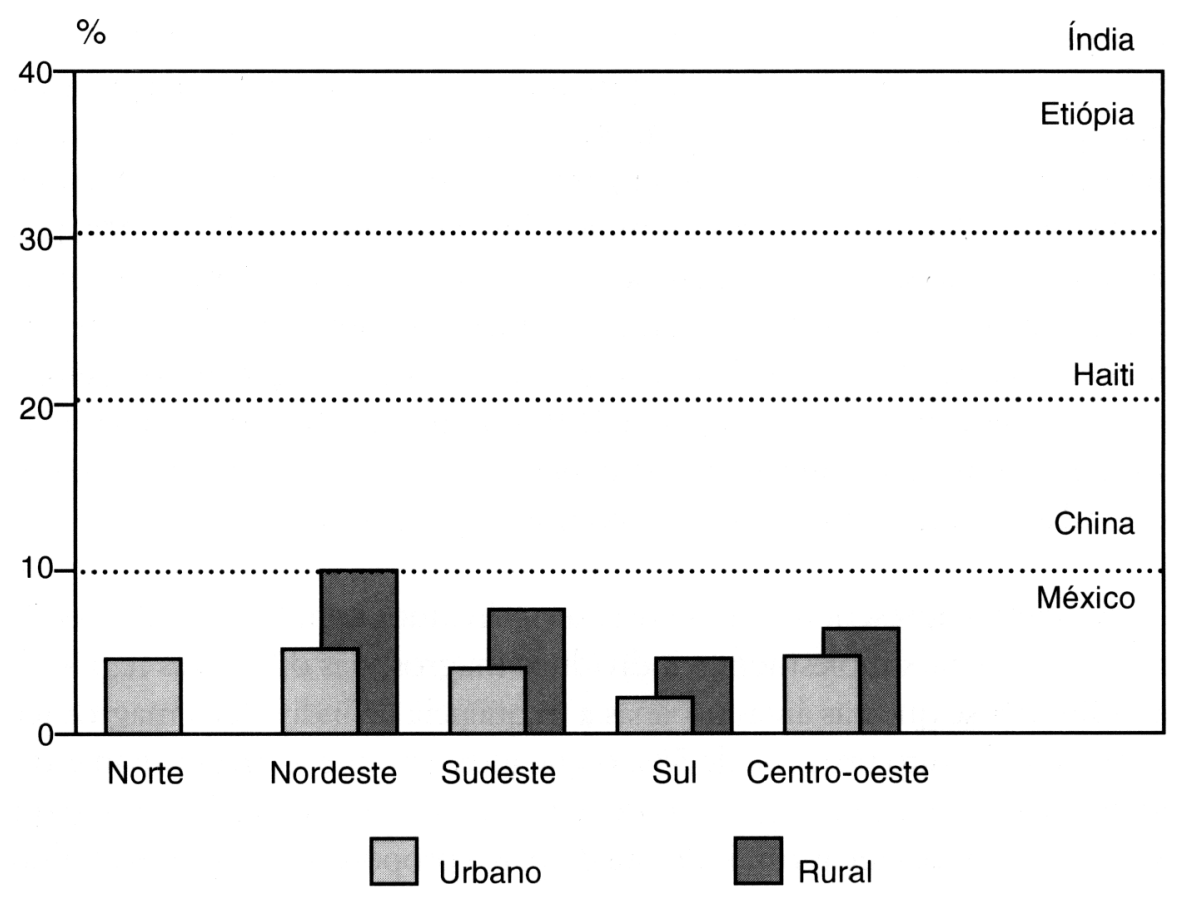

Figura 3 - Prevalência de adultos magros. Brasil, 1989.

A figura 4 procura descrever o comportamento das reservas energéticas dos indivíduos ao longo das idades no meio urbano e no meio rural. Nas áreas urbanas, verifica-se que a proporção de indivíduos magros mantém-se entre $3 \% \mathrm{e}$ $4 \%$ dos 25 aos 65 anos de idade, superando o limiar de $5 \%$ apenas entre os idosos $(8,5 \%)$. Este quadro confirma a hipótese de que a deficiência energética não alcança relevância epidemiológica na população urbana do país, podendo-se atribuir a ligeira elevação da proporção de indivíduos magros entre os idosos a complicações de saúde próprias da velhice. Nas áreas rurais, a proporção de indivíduos magros mantém-se próxima ao limiar de $5 \%$ apenas entre os adultos jovens ( 25 a 44 anos), eleva-se a $8 \%-9 \%$ entre os adultos de meia idade ( 45 a 64 anos) e chega a quase $15 \%$ entre os idosos. A relativa proteção contra a deficiência energética observada entre os adultos jovens do meio rural e a inclusão dos adultos de meia idade, ao lado dos idosos, entre os grupos expostos à deficiência, são fatos intrigantes e cuja explicação exige que se considerem informações com as quais não contamos no momento. A título de hipótese, cogitamos a possibilidade de que complicaçóes de saúde poderiam começar mais precocemente no meio rural e/ou de que adultos de meia idade, tanto quanto os idosos, teriam maior dificuldade de competir no mercado de trabalho rural, que demanda essencialmente grande capacidade física. 
$\%$ IMC $<18.5 \mathrm{~kg} / \mathrm{m}^{2}$

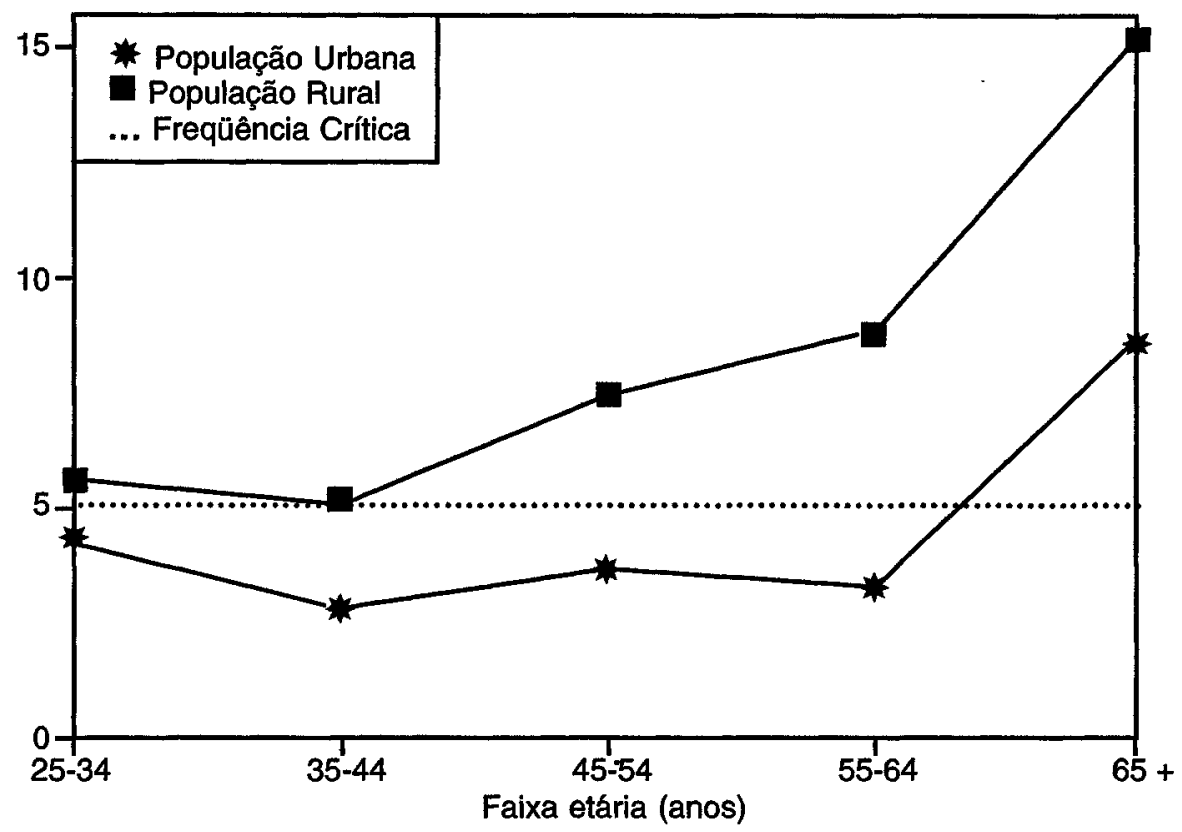

Figura 4: Prevalência de adultos magros segundo faixa etária.

Brasil, 1989.

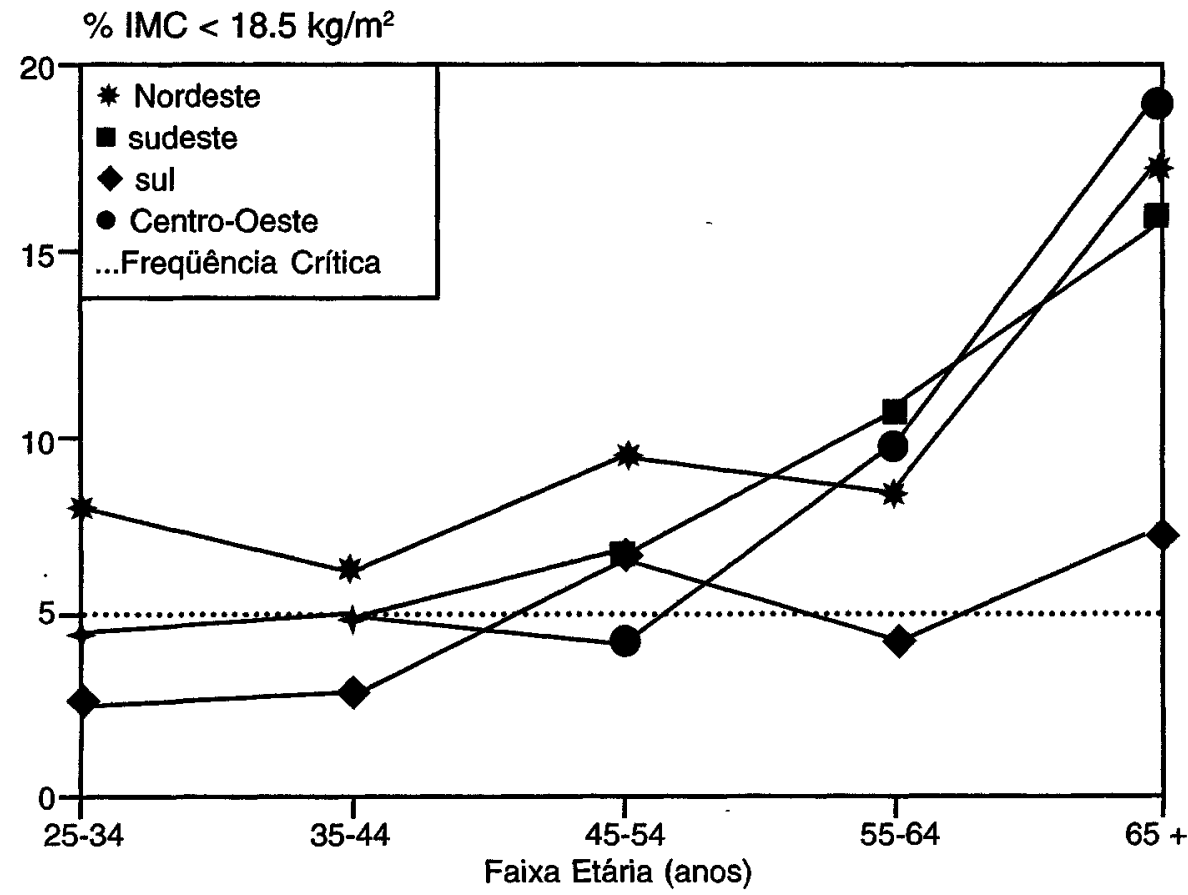

Figura 5: Prevalência de adultos magros segundo faixa etária.

Populaçōes rurais, 1989. 
A figura 5 descreve o comportamento das reservas energéticas ao longo das idades na população rural das diferentes macroregiōes do país. Em um extremo, vêse a situação do Sul rural, onde adultos jovens, de meia idade e mesmo idosos parecem relativamente protegidos da deficiência energética. No outro extremo, encontra-se o Nordeste rural, onde todos os grupos etários, mesmo adultos jovens, estão expostos à deficiência energética. Nas demais regiốes, essa deficiência está claramente presente na população rural apenas a partir dos 55 anos de idade.

\section{Conclusôes}

A pobreza, no Brasil, medida pela insuficiência de renda, assume proporçóes enormes e dissemina-se por todas as regiōes e áreas do país, castigando em particular as populações rurais e urbanas da região Nordeste e as populaçóes rurais das demais regióes brasileiras.

A desnutrição, medida pelo retardo do crescimento infantil, também assume grandes proporções no país e está presente em todas as suas regiốes e áreas. A população mais afetada, neste caso, é aquela que reside nas regiões Norte e Nordeste. As populaçóes rurais são mais atingidas do que as urbanas, mas o contraste Norte/Sul é o que chama mais a atenção, a ponto de as populaçóes urbanas do Norte e Nordeste apresentarem prevalências de desnutrição substancialmente superiores às encontradas nas populaçóes rurais do Centro-Sul.

A comparação da situação da desnutrição infantil no Brasil com estatísticas provenientes de outros países em desenvolvimento situa os estados das regióes Norte e Nordeste junto a países muito pobres da África e da América Latina. A mesma comparação situa os estados das regiões Sul, Sudeste e CentroOeste ao lado de um pequeno e privilegiado grupo de países em desenvolvimento relativamente ricos e /ou reconhecidos como contando com sistemas de seguridade social muito eficazes.

A fome, medida pelas reservas energéticas da população adulta, tem incidência restrita no país, afetando de forma clara apenas a população rural do Nordeste, ainda assim em grau leve ou moderado, de acordo com padróes internacionais. Apresentam-se notavelmente protegidas da fome as populaçóes urbanas de todas regióes do país, incluindo as que vivem nas regiōes Norte e Nordeste e a população rural que vive no Sul (mais dados seriam necessários para se esclarecer inteiramente a situação da deficiência energética nas demais populaçóes rurais brasileiras).

As distinções identificadas na magnitude e padrão de distribuição da pobreza, da fome e da desnutriçáo confirmam a natureza distinta dos problemas, tal como sustentada na introdução deste trabalho, ao mesmo tempo em que deter- 
minam implicações importantes na definição de prioridades e alvos parà intervenção governamental.

Salvo improváveis modificações no quiadro encontrado em fins da década de 80, medidas antipobreza (elevação do salário mínimo, programa de renda mínima, subsídios ao consumo etc), ainda que justificadas no país como um todo, deveriam atender preferencialmente e com mais recursos a região Nordeste e, de modo geral, os trabalhadores rurais de todo o país. Açóes específicas de combate à desnutrição (diagnóstico e acompanhamento médico, suplementação alimentar seletiva, prevenção e tratamento de doenças infecciosas etc) deveriam ter como alvo prioritário a população de crianças que vive nas regióes Norte e Nordeste. Finalmente, ações específicas contra a fome (particularmente a distribuição gratuita de alimentos às famílias) encontrariam plena justificativa, desde que implementadas nas áreas rurais do Nordeste brasileiro, podendo-se prever, de modo geral, pouco ou nenhum impacto para açóes realizadas no âmbito das populaçóes urbanas do país.

Referências bibliográficas

HOFFMANN, R. Pobreza, insegurança alimentar e desnutrição no Brasil. São Paulo, texto apresentado no Seminário Pobreza, fome e desnutrifão no Brasil, organizado pelo Grupo de Trabalho Segurança Alimentar do Instituto de Estudos Avançados da Universidade de São Paulo, 1994.

ONÍS, M.; Monteiro, C.A.; AKRÉ, J. \& CLUGSTON, G. The worldwide magnitude of protein-energy malnutrition: an overview from the WHO global database on child growth. Bull. Wld. Hlth. Org., v. 71, n. 6, p. 703-712, 1993.

SEADE. Definição e mensurậão da pobreza na região metropolitana de São Paulo: uma abordagem multi-setorial. São Paulo, Fundação Sistema Estadual de Análise de Dados - Seade, 1992.

UNDP. Human developing report 1992. New York, Oxford University Press, 1992.

UNDP. Human developing report 1993. New York, Oxford University Press, 1993.

WHO Working Group. Use and interpretation of anthropometric indicators of nutritional status. Bull. Wld. Hlth. Org., v. 64, p. 929-941, 1986.

Carlos Augusto Monteiro é professor titular do Departamento de Nutrição da Faculdade de Saúde Pública da Universidade de São Paulo e coordenador cientifico do Núcleo de Pesquisas Epidemiológicas em Nutrição e Saúde da USP (Nupens).

Texto apresentado no seminário Pobreza, fome e desnutriçáo no Brasil, organizado pelo Grupo de Trabalho Segurança Alimentar do IEA-USP em 2 de dezembro de 1994. 